\title{
Complex Sequence of the English Nominal Group
}

\author{
Esther Olayinka Bamigbola \\ Adekunle Ajasin University, Akungba-Akoko, Nigeria
}

\begin{abstract}
The nominal group is an important aspect of English and other languages and requires specific attention because of its complex structure and sequence. This study examines how sequencing affects users' understanding and interpretation of the English nominal group and attempts to prescribe guidelines to the different challenges which the complex ordering of the nominal group poses to users of English as a second language. The findings of the study indicate that the complex ordering of the nominal group has a significant impact on their semantic effects in any discourse, and many of the difficulties users of English as a second language are faced with have to do with lack of adequate understanding of the structure and usage of the nominal group. Some of these problems can be addressed through a comprehensive study and examination of linguists' explanation of the nominal group and practical application of their guidelines. A functional approach to the study of the group will help second language learners of English to have a better understanding of its structure.
\end{abstract}

Keywords: functional grammar, nominal group, ordering, language teaching

\section{Introduction}

Ordering is a very important aspect of the grammar of any language. As an important feature, ordering has influence on the syntactic, semantic, pragmatic, and even phonological impression of statements, groups, and words. English language users cannot do without mastery of the ordering of the nominal group. The nominal group has both simple and complex structures (Halliday, 1985; Akande, 2002).

In the magazines and newspapers examined for this study, different writers used a lot of complex nominal phrases. The study shows as observed by Quirk, Greenbaum, Leech, and Svartvik (1985) in relation to variety, that on the whole, the number of simple nominal groups is more than the complex ones in the general writings of English language users. While the simple nominal groups may be easy to understand, language users are more likely to encounter difficulty with the complex ones (Jimba, 2000). Therefore, this study examines some of the problems which users of English as a second language have in understanding, interpreting, and using complex nominal groups. Based on the findings, the authors recommend some ways language users can overcome such problems, drawing insight from the contributions of functional grammarians.

\section{Theoretical Background}

The works of linguists who have earlier discussed the English nominal phrase spread through different grammar groups (Allen, 1972; Allerton, 1979; Berry, 1975; Blake, 1988; Butler, Hidalgo, Lavid, \& Downing,

Esther Olayinka Bamigbola, lecturer, Ph.D., Department of English Studies, Adekunle Ajasin University. 
2007). This is the reason for the use of the terms "phrase" and "group" interchangeably, since some of the linguists use the former (Chomsky, 1965; Hudson, 1973; Gleason, 1961) while some others use the latter (Bloor \& Bloor, 2004; Boadi, Grieve, \& Nwankud, 1968; Halliday \& Matthiessen, 1999). According to Boadi et al. (1968), group is a term applied to a sequence of words used together. Where one of the words in the group (basically the essential word-head) can be used in the place of the group without changing the grammatical structure of the words, then the sequence makes up a group.

Halliday (1994) defines group as the rank in the lexicogrammar between clause and word. It functions in clauses and are composed of words. A group, he further explains, is in many respects a set of words or a word complex. The structure is that of head and modifier(s) (Halliday, 1994). Obilade (1976) in his discussion of the nominal phrase in West African Pidgin English, uses Halliday's systemic model to explain the various meanings expressed in the nominal phrase and how they are given grammatical expression. He defines the nominal phrase in terms of its constituents (modifiers, head, and qualifiers) and in terms of a higher unit, the clause (where in the structure of the clause a nominal phrase functions).

Gleason (1961) observed that "the English nominal phrase has a complicated structure involving at least six distinguishable positions before the head, each fill-able by a class or set of classes of words or phrases" (p. 409). The noun phrase occurs in different positions in English sentences. When a nominal phrase contains only the essential word (the head) or with a determiner or marker, it is said to have a simple structure, e.g.,

Example (1) - Boy

$$
\begin{aligned}
& \text { - A lorry } \\
& \text { - The man } \\
& \text { - Young ladies } \\
& \text { - An elephant }
\end{aligned}
$$

In a complex noun phrase, there are several components. Determiners and modifiers come before the head of a noun group while qualifiers come after the head. The reason for the complexity of some nominal phrases, as earlier stated, is an attempt by writers to reshape several simple sentences to come within nominal group structure and form a single statement. Often in English, it is possible to combine several simple facts into one single sentence with the use of a very complex noun phrase. This is made possible by expanding and elaborating the phrase to a considerable degree. For example,

Example (2) All of the five quite old buildings there at the bend of the country's most famous river are factories.

The sequential pattern of items in a noun group is regulated. If for example there are several adjectives between the article and the noun, they fall into order of classes. Thus, adjectives denoting size and shape precede adjectives of color (Greenberg, 1977). For example, it is acceptable to say "a big red bucket" but not "a red big bucket".

Martin, Matthiessen, and Painter (2010) pointed out that the nominal group has the potential for including embedded groups/phrases and clauses in its structure. Greenberg (1977) compared the possible expansion of noun phrase with infinity in mathematics, whereby the natural numbers constitute an infinite set because given any number, one can always name the next higher number. What this simply means is that in the noun phrase, adjectives may be added without limit. Hence, the number of possible noun phrases or sentences is infinite, 
although each individual instance must, of course, be finite in length. This is what the transformational generative grammarians explained as recursiveness, that is, the rule which expands sentence and the rule which expands noun phrase (Jackendoff, 1974; Peters \& Ritchie, 1973). Jacob and Peter (1968) represent these rules as shown below:

$\mathrm{S} \rightarrow \mathrm{NP}$ AUX VP

$\mathrm{NP} \rightarrow \operatorname{ART} \mathrm{N}(\mathrm{S})$

These rules, they explained, could be applied one after the other to each other's output in a derivation, which can be made as long as is desired.

It is generally accepted that language is linearly manifested, that is, it is serial in presentation. Muir (1972) pointed out that in speaking or writing, items follow each other in temporal or spatial succession. However, cases of internal discontinuities within a noun phrase may occur. Quirk et al. (1985) observed that in most cases, the part usually affected by discontinuity is the post-modification of noun phrases, and the units often postponed are the appositive clauses. However, other post-modifying clauses and even phrases can also be postponed. The reason why writers sometimes postpone part of a noun phrase is to achieve an end-focus.

This study makes use of insights from the different theories of grammar with the hope of clarifying some aspects of the noun phrase that still constitute problems for users of English as a second language. The functional description of the English nominal group as given by systemic functional linguists is what will be examined next.

In systemic functional linguistics, the set of terms that show how the clause can be broken down into functional constituents are referred to as participant, process, and circumstances. The participant element is realized by a nominal group, i.e., the "THING" element (Halliday \& Matthiessen, 2004; Martin et al., 2010).

Like the English clause, the nominal group is a combination of three distinct functional components which express three largely independent sets of semantic choice: the ideational (what the nominal group is about), the interpersonal (what the group is doing as a verbal exchange between speaker and listener, or writer and reader), and the textual (how the message is organized — related to the surrounding text and the context in which the group occurs). In a clause, each metafunction is virtually a complete structure, and the three structures combine into one in interpretation. However, beneath the clause - in phrases and groups, such as the nominal group - the three structures are incomplete in themselves and need to be interpreted separately, "as partial contributions to a single structural line". In nominal groups, the ideational structure is by far the most significant in premodifying the head. To interpret premodification, the ideational metafunction splits into two dimensions: the experiential and the logical (Halliday, 1985).

\section{Experiential Dimension of Premodifiers}

The experiential dimension concerns how meaning is expressed in the nominal group as the organization of experience. However, it is not always that the head is modified to constitute a nominal group. Thus, there are four types of nominal group:

(1) the head alone, e.g., "dresses";

(2) the head with premodifiers, e.g., "Those two beautiful long party dresses";

(3) the head with a qualifier, e.g., "Those two beautiful long party dresses which you bought at the shop near the bakery"; and 
(4) the full structure of premodification and qualification, e.g., "Those two beautiful long party dresses which you bought at the shop near the bakery that sells those cakes which your father likes".

\section{Functions of the Premodifiers}

In the above example, the premodifiers characterize the head on what is known as the uppermost rank. In some formal grammars, all of the premodifying items in the example above, except for "Those", would be referred to as adjectives, despite the fact that each item has a different grammatical function in the group. An epithet indicates some quality of the head: "long" is an experiential epithet, since it describes an objective quality that can be experienced by everyone; by contrast, "beautiful" is an interpersonal epithet, since it is an expression of the speaker's subjective attitude towards the dresses, and thus partly, a matter of the relationship between speaker and listener; "party" is a classifier, which indicates a particular subclass of the head (not sport or office but party dresses); a classifier cannot usually be intensified ("very party dresses" is ungrammatical); "two" is a numerator, and unlike the other items, describes not a quality of the head but its quantity.

\section{Ordering of the Premodifiers}

The experiential pattern in nominal groups opens with the identification of the head in terms of the immediate context of the speech event — the here-and-now—what Halliday (1985) calls "the speaker-now matrix". Take, for example, the first word of the nominal group exemplified above: "those": "those dresses", as opposed to "these dresses", means "you know the dresses I refer to- the ones over there, not close to me"; distance or proximity to the immediate speech event could also be in temporal terms (the ones you picked last week, not today), or in terms of the surrounding text (the dresses mentioned in the previous paragraph in another context, not in the previous sentence in the same context as now) and the assumed background knowledge of the listener/speaker ("the dresses" as opposed to " $a$ dress" means "the one you know about"). The same function is true of other deictics, such as "my", "all", "each", "no", "some", and "either": They establish the relevance of the head - they "fix" it, as it were-in terms of the speech event.

There is a progression from this opening of the nominal group, with the greatest specifying potential, through items that have successively less identifying potential and are increasingly permanent as attributes of the head. Halliday (1985) also pointed out that, "the more permanent the attribute of a thing, the less likely it is to identify it in a particular context" (of the speech event). The most permanent item is the head itself. This pattern from transient specification to permanent attribute is said to explain why the items are ordered as they are in a nominal group. The deictic ("those") comes first; this is followed by the numerative, if there is one ("two"), since the number of dresses, in this case, is the least permanent attribute; next comes the interpersonal epithet which arising from the speaker's opinion, is closer to the speaker-now matrix than the more objectively testable experiential epithet ("long"); then comes the more permanent classifier ("party", a type of dress), leading to the head itself. This ordering of increasing permanence from left to right is why it is more appropriate to say "her new blue dress" rather than "her blue new dress": The newness will recede sooner than the blueness.

Therefore, there are four broad groups which reflect the structure of premodification in a nominal group. These are deictic, numerative, epithet, and classifier. Usually, these should be ordered as mentioned above to avoid ambiguity. However, it should be noted that the boundaries between these four groups are not watertight. The same word can act as a classifier in a nominal group and can also be used as an epithet. For example, 
Example (3) (a) public support (classifier)

(b) a very public occasion (epithet)

In Examples (3a) and (3b), the same word "public" is used as both classifier and epithet. As such, language users should not think that every word can be labelled once and for all without considering its function in context. It should also be noted that these categories could be refined further. As earlier pointed out by Greenberg (1977), one could distinguish between epithet expressing size (e.g., big, small) and color (red, white) noting that the former typically precedes the latter (a big red car) and that it seems more appropriate to intensify size than color, "a very big dog" but not "a very brown dog".

\section{Logical Dimension of Premodifiers}

The logic of the group in English is said to be recursive, based on successive subsets: Working leftwards from the head, the first question that can be asked is "what kind of dresses?" (party dresses.) Then, "what kind of party dresses?" (long party dresses.) "What kind of long party dresses?" (beautiful long party dresses.) "What kind of beautiful long party dresses?" (Here the recursive logic changes since this is a multivariate, not a univariate, nominal group. The question now is, "How many beautiful long party dresses?" and after that, "How do those two beautiful long party dresses relate to me the speaker/writer, now?" ("those ones"). In contrast however, the logical questions of a univariate group would be unchanged right through, typical of long strings of nouns in news headlines and signage, e.g., "International departure lounge ladies' first-class washroom".

\section{The Head}

According to Halliday (1985), the "THING" (head) is the semantic core of the nominal group. It may be common noun, proper noun, or (personal) pronoun. The personal pronoun represents the world according to the speaker, in the context of a speech exchange. The basis distinction is into speech roles (I, you) and other roles (he, she, it, they). There is also the generalized personal pronoun (one). Proper names in a nominal group may consist of one word or many, e.g., Busayo, Adekunle Ajasin University.

Referent for personal pronouns is defined interpersonally, by the speech situation and with proper names it is defined experientially (i.e., there exists only one at least in the relevant body of experience). As such, both pronouns and proper names usually occur without any other elements of the nominal group. Sometimes however, they need further defining such as: "you in long red party dress"; "Henry George the Eighth"; "Henry George (with surname as qualifier)", and sometimes proper nouns may carry attitudinal epithets like: "little Busayo"; "pretty little Busayo Adebayo of Awolowo Avenue". Common nouns are accompanied by deictics and often other elements.

Things are grouped into two semantic categories in English language, i.e., discrete—countable/count nouns and continuous - uncountable/mass nouns. Mass nouns are grouped with singular count nouns if specific, and with plural count nouns if non-specific (Halliday \& Matthiessen, 2004).

\section{The "THING"}

The head of a nominal group in a univariate structure may not be the head in a multivariate structure. There is always a head in the nominal group (unless it is branched) but there may be no "THING" (see Halliday, 1985, p. 173). 


\section{The Post-modifiers}

The post-modifier is by far the most intricate part of a nominal group, and it can be extremely complex. It is usually a phrase or a clause, e.g.,

Example (4) the dress which you bought at that shop near the bakery that sells those cakes which your father likes

Example (4) is a nominal group with the dress as head and everything after, qualifying the dress. With only rare exceptions, all qualifiers are rank-shifted, i.e., in structure, they are of a rank higher than or at least equivalent to that of the nominal group. Looking at Example (4), the phrases, "which you bought", "at the shop", "near the bakery" are adjectival and prepositional phrases embedded within the nominal group; the prepositional phrases "at the shop" and "near the bakery" contain nominal groups ("the shop"; "the bakery"), comprising the heads ("shop"; "bakery"), and the deictic ("the") which indicates whether some specific subset of the head is intended (a specific shop and a bakery that can be identified from the context). By contrast, "Those" is a deictic on the uppermost rank and is applied to the head on the uppermost rank, "dresses"; "those" means "You know which dresses I mean - the ones over there". Thus, the rank-shifting in the group is as illustrated below.

[[[the dress [which you bought] [at that shop] [near the bakery] [[that sells those cakes]] [[which your father likes]] ]]]

Group, like clauses can form nexuses by a combination of paratactic or hypotactic type of logico-semantic relation (Halliday \& Matthiessen, 2004). Nominal groups can be linked paratactically by apposition and by co-ordination, the former functioning as elaborations and the latter as extensions. Nominal groups can also be linked by enhancement and in rare cases by projection. Examples are as follows:

Example (5) (a) Her latest novel, "The Joy of Motherhood"

(APPOSITION)

(b) Either you or your sister

(EXTENSION)

(c) All the police, and hence the inspector

(ENHANCEMENT)

(d) The student's thesis, a brilliant work...

(PROJECTION)

Hypotactically, nominal groups are based only on expansion functioning as elaboration and extension, e.g., Example (6) (a) the dress which you bought

(ELABORATION)

(b) His ambition as well as his plans

(EXTENSION)

The knowledge of the various relationships discussed above will help language users to achieve cohesion and coherence in their writing and speech.

\section{Test Design and Analysis of Results}

Selected complex nominal groups/phrases from passages in textbooks, articles in magazines, newspapers and students' essays were examined based on Quirk et al. (1985) and Halliday and Matthiessen (2004) models. A test was administered and articles from magazines and newspapers were considered. The test was administered on randomly selected students in the second year of a public, co-educational senior secondary school at Ilorin, the headquarters of Kwara State, Nigeria. The class, comprising of three arms — science, arts, and commercial—was chosen because it is preparatory for the Senior Secondary School Certificate Examination. The test administration and analysis of results are discussed below, under the various aspects of nominal group complexes. 


\section{Non-explicitness of Post-modification}

The researcher observed, as did Quirk et al. (1985), that English language users seem to have less problem with the finite relative clause because of the presence of the explicit tense is/was. Explicitness is, however, reduced with the use of non-finite -ing clause because of the absence of is/was tense and worse still is the non-explicitness with the use of the prepositional phrase from which the verb indicating a specific posture is absent. Another instance of reduction in explicitness is the use of pro-form to represent a sentence. Two of the test items given to the students were directed at examining the level of difficulty in understanding noun phrases in this category. In the first sentence, the non-finite -ing was used, while in the second, prepositional phrase was used in which there was no verb, indicating specific action. Different possible interpretations were given for each statement and each student is to choose the option he/she feels best interprets each sentence. The statements and the options are reproduced below:

Choose the option that best interprets each of the following statements:

Statement 1: The students sitting in the classroom saw the thief.

(a) The students sitting, not all those in the classroom saw the thief.

(b) The students sitting in the classroom and not those sitting outside saw the thief.

(c) The students were sitting in the classroom when they saw the thief.

Statement 2: The bicycle man came here this morning.

(a) The man riding bicycle came here this morning.

(b) The man who rides a bicycle came here this morning.

(c) The man who owns a bicycle came here this morning.

(d) The man on the bicycle came here this morning.

Eighty students attempted these questions. The results are presented in Tables 1-2.

Table 1

Summary of Results on Interpretation of Statement 1

\begin{tabular}{lll}
\hline Option & No. of respondents & Percentage \\
\hline (a) & 15 & 18.75 \\
(b) & 28 & 35.0 \\
(c) & 37 & 46.25 \\
Total & 80 & 100 \\
\hline
\end{tabular}

Table 2

Summary of Results on Interpretation of Statement 2

\begin{tabular}{llc}
\hline Option & No. of respondents & Percentage \\
\hline (a) & 30 & 37.5 \\
(b) & 24 & 30.0 \\
(c) & 15 & 18.75 \\
(d) & 11 & 13.75 \\
Total & 80 & 100 \\
\hline
\end{tabular}


From Table 1, the students selected different options based on how they understood Statement 1. Out of the 80 respondents, 15 representing $18.75 \%$ selected option (a), 28 representing $35 \%$ chose (b) while 37 representing $46.25 \%$ opted for (c).

In response to Statement 2, 30 students representing 37.5\% selected (a), 24 representing 30\% opted for (b), those that chose option (c) were 15 representing 18.75\% while the remaining 11 representing $13.75 \%$ selected option (d). These results confirm the fact that the two statements are opened to different interpretations due to non-explicitness of the post-modifiers.

\section{Wrong Use of Restrictive Modification}

The students were instructed to insert punctuation marks (specifically commas) in appropriate places in each of the two sentences. On the whole, 60 cases of deviations were recorded. These deviations are grouped into types (a)-(d) in Table 3.

Table 3

Errors Recorded on Wrong Use of Restrictive Modification

\begin{tabular}{llc}
\hline Type of error & No. of cases recorded & Percentage \\
\hline Unnecessary use of restrictive clauses & 12 & 20.0 \\
Wrong use of restrictive clauses with non-nominal antecedents & 10 & 16.7 \\
Use of non-restrictive modifications for non-assertive heads & 18 & 30.0 \\
Wrong use of non-restrictive modification with non-specific determiners & 20 & 33.3 \\
Total & 60 & 100 \\
\hline
\end{tabular}

Twelve representing $20 \%$ of the 60 cases were errors of unnecessary use of restrictive clauses. Ten representing 16.7 were errors of type (b), which is the wrong use of restrictive clauses with non-nominal antecedents while 18 representing 30\% were errors of type (c), i.e., the use of non-restrictive modifications for non-assertive heads. The responses of the remaining 20 representing $33.3 \%$ are grouped under type (d) error, which is the wrong use of non-restrictive modification with non-specific determiners.

\section{Incorrect Ordering of Adjectives}

In order to test users' mastery on ordering of noun phrase elements, particularly the arrangements of adjectives, a multiple choice question was given with only one correct option. Table 4 contains the summary of the responses.

Table 4

Summary of Responses on Ordering of Adjectives

\begin{tabular}{lll}
\hline Option & No. of responses & Percentage \\
\hline Correct option & 19 & 23.75 \\
Incorrect option & 61 & 76.25 \\
Total & 80 & 100 \\
\hline
\end{tabular}

The responses of the students show that majority, 61 representing $76.5 \%$, chose the incorrect options. Only 19 , representing $23.5 \%$ chose the correct option.

\section{Incorrect Sequence of Premodifiers}

One of the test items was directed at examining the students on ordering of premodifiers. This item required the choice of the correct option among four alternatives. The result is presented in Table 5 . 
Table 5

Summary of Responses on Ordering of Premodifiers

\begin{tabular}{lll}
\hline Option & No. of responses & Percentage \\
\hline Correct option & 42 & 52.5 \\
Incorrect option & 38 & 47.5 \\
Total & 80 & 100 \\
\hline
\end{tabular}

From Table 5, 42, representing 52.5\% chose the correct option while the remaining 38 , representing $47.5 \%$ selected the incorrect options. These results indicate that learners also need to be acquainted with the rules guiding the arrangement of premodifiers so as to help them avoid unnecessary errors.

\section{Ambiguity Resulting From Discontinuity of Noun Phrase}

The part usually affected by discontinuity is the post-modification of noun phrase and the units often postponed are the appositive clauses. In an attempt to reorder constituents of noun phrase to achieve specific information goal, the resulting statement may be opened to ambiguity. To test the learners on this aspect, a question was given for which the students were required to choose the option that is ungrammatical and unacceptable among five alternatives. The different alternatives involve shifting the position of some elements of a statement with one of the forms opened to ambiguity. The result of their responses on that test item is presented in Table 6.

Table 6

Summary of Responses to Item on Discontinuity of Noun Phrases

\begin{tabular}{lll}
\hline Option & No. of students & Percentage \\
\hline Correct option & 65 & 81.25 \\
Incorrect option & 15 & 18.75 \\
Total & 80 & 100 \\
\hline
\end{tabular}

Out of 80 respondents, 65 , representing $81.25 \%$ were able to detect the statement that is ambiguous. The other 15 , representing $18.72 \%$ were unable to detect the ambiguous option.

\section{Discussion and Recommendations}

From the above analysis, the authors found that the complex ordering of the English nominal group has a significant impact on language users' understanding and interpretation of statements. Consequently, many of the difficulties confronting users of English as a second language have to do with inadequate mastery of the structure of the nominal group. This agrees with the opinion of Okanlawon and Oluga (2008). Some of these problems can be addressed through a comprehensive study and examination of the explanations given by different linguists on the group.

Based on the findings of this study, the following recommendations are made which should help to reduce the errors that result from wrong interpretation and usage of complex nominal groups. Writers need to ensure that readers are not presented with ambiguous statements which could easily be misinterpreted. This is because the paralinguistic signals which accompany speech such as gesture, and could help the hearer interpret some omitted elements and intentions, are totally absent in written texts. Also, it should be noted that in speech or informal writings, elements of familiarity between speaker and hearer or writer and reader play a remarkable role in the 
interpretation of non-explicit statements. However, in formal writings, such familiarity does not always exist. Therefore, the writer should be explicit enough in his use of language so as to avoid cases of misinterpretation. It should be noted that reduction in the explicitness in any noun phrase is closely tied to the linguistic and situational context. Also from the findings, it is recommended that writers must avoid, as much as possible, discontinuity in their expressions, so as to guide against misinterpretation.

Systemic functional linguistics presents a very functional model for analyzing the various components of language (Obilade, 1976; Akerejola, 1990). It is a very useful tool for tackling many of the problems that relate to the structure of languages. This is because of its perception of the dynamic relationship between language and context. And the knowledge of the context allows language users to make predictions about the lexicogrammar of a text. Therefore, it is also recommended that a functional approach to the study of the nominal group will help second language learners of English have a better understanding of its structure.

\section{Conclusion}

In this study, the difficulties encountered by users in understanding and interpreting complex nominal groups are examined. Using the models of Quirk et al. (1985) and Halliday and Matthiessen (2004), the various problems posed by the complex noun group as evidenced in some texts were analyzed. The findings show that the structure of the English nominal groups can be potentially very complex. As such, users of English language need adequate mastery of its structure and usage.

\section{References}

Akande, A. T. (2002). Structural complexity and the acquisition of the hq (headword/qualifier) nominal group type in English. Nordic Journal of African Studies, 11(2), 236-248.

Akerejola, E. S. (1990). The application of the concept of unit in systemic functional grammar to an analysis of Oko (Ogori) (Master's thesis). A. B. U. Zaria, Nigeria.

Allen, R. L. (1972). English grammar and English grammar. New York: Charles Scribner \& Sons.

Allerton, D. J. (1979). Essentials of grammatical theory: A consensus view of syntax and morphology. Cambridge: Cambridge University Press.

Berry, M. (1975). Introduction to systemic linguistics/structures and systems. London: B. T. Batsford Ltd..

Blake, N. F. (1988). Traditional English grammar and beyond. London: Macmillan Ltd..

Bloor, T., \& Bloor, M. (2004). The functional analysis of English (2nd ed.). London: Edward Arnold.

Boadi, L. A., Grieve, D. W., \& Nwankud, B. (1968). Grammatical structure and its teaching. Ibadan: African University Press.

Butler, C., Hidalgo, D. R., Lavid, J., \& Downing, A. (2007). Functional perspectives on grammar and discourse: In honour of Angela Downing. Amsterdam: J. Benjamins.

Chomsky, N. (1965). Aspects of the theory of syntax. Cambridge: Mass MIT Press.

Gleason, H. A. (1961). An introduction to descriptive linguistics (Rev. ed.). London: Holt Rinehart and Winson.

Greenberg, J. H. (1977). A new invitation to linguistics. New York: Anchor Books.

Halliday, M. A. K. (1985). An introduction to functional grammar. London: Edward Arnold.

Halliday, M. A. K. (1994). An introduction to functional grammar. London: Edward Arnold.

Halliday, M. A. K., \& Matthiessen, C. M. I. M. (1999). Construing experience through meaning: A language-based approach to cognition. London and New York: Continuum.

Halliday, M. A. K., \& Matthiessen, C. M. I. M. (2004). An introduction to functional grammar. London: Arnold.

Hudson, R. A. (1973). English complex sentences: An introduction to systemic grammar. London: North Holland Publishing Co..

Jackendoff, R. (1974). Semantic interpretation in generative grammar. Cambridge: MIT Press.

Jacobs, R. A., \& Peter, S. R. (1968). English transformational grammar. Waltham: Blaisdell.

Jimba, E. O. (2000). The English nominal phrase: Complexity of its sequence (Unpublished master's thesis). A. B. U. Zaria, Nigeria. 
Martin, J. R., Matthiessen, C. M. I. M, \& Painter, C. (2010). Deploying functional grammar. Beijing: The Commercial Press. Muir, J. (1972). A modern approach to English grammar. London: Batsford.

Obilade, A. O. (1976). The nominal phrase in West African Pidgin English (Nigeria) Northwestern University (Ph. D. dissertation). Evanston, Ilinois Xerox University Microfilms, Ann Arbor, Micchigan.

Okanlawon, B., \& Oluga, S. (2008). Ambiguity and nominal group multiple post modification in the written English of some selected Nigerian polytechnics. African Research Review, 2(1), 124-151.

Peters, S., \& Ritchie, R. (1973). On the generative power of transformational grammars. Information Sciences, 6, 49-83.

Quirk, R., Greenbaum, S., Leech, G., \& Svartvik, J. (1985). A comprehensive grammar of the English language. London: Longman. 